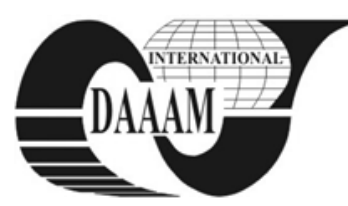

Annals of DAAAM for 2012 \& Proceedings of the 23rd International DAAAM Symposium, Volume 23, No.1, ISSN 2304-1382 ISBN 978-3-901509-91-9, CDROM version, Ed. B. Katalinic, Published by DAAAM International, Vienna, Austria, EU, 2012 Make Harmony between Technology and Nature, and Your Mind will Fly Free as a Bird Annals \& Proceedings of DAAAM International 2012

\title{
ADAPTRONICS - NEW CONCEPT FOR THE FUTURE OF ADVANCED ENGINEERING AND INTELLIGENT AUTOMATISED MANUFACTURING
}

\author{
GHEORGHE, I[on] G[heorghe]; ISTRITEANU, S[imona] - E[lena]; \\ CONSTANTINESCU, A[lexandru] \& DESPA, V[eronica]
}

\begin{abstract}
The paper treats new concept of adaptronics for the future of advanced engineering and intelligent automation, by bringing news and discoveries in the field of basic and applied science of mechatronics and integronics and as development vector of know-how in high-tech advanced domain by adapting scientific, complex, structural, functional and decisional of structures, products and systems, to change the operating mode of environment requirements, to control in active mode the vibration, the noise and the deformation, to recover energy from mechanics and inertial vibrating systems and to influence and monitories all structures of any kind.
\end{abstract}

Keywords: adaptronics, advanced engineering, integrated science, mechatronics, integronics

\section{INTRODUCTION}

The new high-tech intelligent and adaptive science of Adaptronics is defined in the concept of the author, in Romania as ,, a combination and synergy of innovative multi-technology engineering and multi-disciplinary fundamental new knowledge in multi-structural Mechatronics, multi-structural Integronics, Advanced Intelligent Materials Science, sensors and actuators Architecture, Computer Science, Intelligent Measurement Technology and intelligent automatic Control. (Fig. 1). At international and European scale and with the original contributions of the author, Adaptronics is defined by several variants, as follows : $>$ it is the „Advanced knowledge that facilitates high performance of intelligent systems [1] (mechatronics, integronics and high-tech systems) and the competitive development of new, innovative products, re-finding the relevance in most effective business areas";

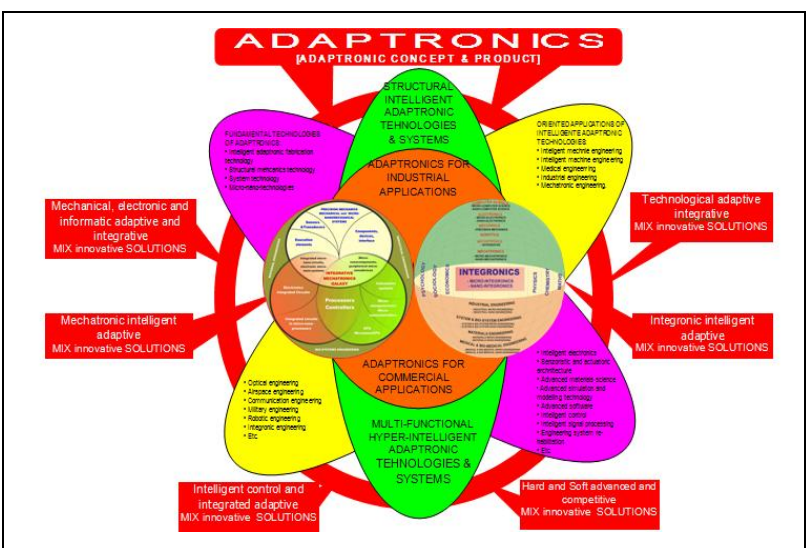

Fig. 1. The new high-tech science of adaptronics

- it is the „hyper-advanced field that completes the innovative developments and potential developments needed for significant upgrades and improvements in intelligent technologies appropriate and necessary on international markets (and national markets) and of the computer-based and cibernerized industry";

- it is the ,integrative high-tech high-performance vector of strategic industries such as high performance mechatronics industry, integronics industry, aerospace industry, intelligent car industry, medical technology, measurement and control technology, intelligent measurement engineering, mechanical and process engineering, manufacturing engineering and automation handling";

- it is the ,intelligent innovative science in significant coverage in national markets, European and international markets, with a strong interlink between it and the businesses that will be needed to continue the rapid advancement in future advanced technology development";

- it is the „forefront of the intelligent high-tech field that supports the intensive transfer of industrial and operational, technology, product and services, leading to economic growth and high levels of labour employment";

- it is the „key technology for the future, becoming more and more an international platform providing knowledge and new knowledge development and use of technical-economic integration of the results of research and development and innovation";

- it is the ,structural active intelligent technology applicable to all industries, opening up completely new possibilities for developing innovative, intelligent materials, sensoric architectures and new actuators and driving components";

- it is the ,mix of structures and multifunctional products that can change the mode of operation and working environment requirements";

- it is the „new design of ultra-mechanical systems, mechatronic multi-structural systems and adaptive multi integronic systems operating in work conditions and requirements, using adaptive and innovative potential for improving the performance of competitive products and with increased flexibility";

- it is a „new technology with central importance to implementing innovative products that respond to competitive growth and change systems and modern 
and efficient assemblies, while reducing development time and increased flexibility";

- it is the „technical-technological system integrator between $\mathrm{R} \& \mathrm{D}$ and innovation-industrial and commercial applications and active exchange of experiences and knowledge transfer with the latest products and systems solutions for components and adaptive structures and current, evolutionary and generative trends";

- it is a ,synergistic and integrative combination of technical and intelligent technology known as intelligent, intelligent materials, intelligent processes [2] describing the ease of building integrated systems and adaptive structures, with the objective of reducing materials, technology and energy for implementation and operation to an absolute minimum, with scenarios and applications focused on trying to simulate natural and vital functions, the ability of biological systems to recognize and automatically correct the dysfunctions of their own structure; this feature is desired primarily for systems and technical structures in areas with essential safety".

Adaptronics, although it has a young history (about 11 years), it was „,created” or „,invented” as an intelligent high-tech field, as an integrating science, as an intelligent engineering, as advanced and innovative technology product i.e. highly competitive, due to new requirements and conditions imposed to new products, while simultaneously creating low-achieving development, with much higher flexibility, with a much higher precision and a much lower price.

\section{INTELLIGENT, FUNCTIONAL AND ADAPTIVE STRUCTURES OF MECHATRONICS, INTEGRONICS AND ADAPTRONICS}

\subsection{Intelligent, functional and adaptive structures of adaptronic Mechatronics}

According to new requirements and contradictions of the process, product, material, technology, application and effect of results in industry, economy and society, the advanced scientific domain «Mechatronics» was developed, modernized and adapted to meet various functional and operational criteria, to reduce material energy and financial resources, operating at an absolute level, improving ergonomics at an optimal level and decreasing costs to the limit. In this sense, the concept and structure of the Mechatronics domain has generatively evolved by replacing or adding new elements, structural and functional components and subsystems on new principles appropriately adapted to new scientific discoveries, to obtain facilities and technical technological and economic effects, required by concrete applications of mechatronic adaptronic products, technologies and services. Thus, in Figure 2, is presented the adaptronic mechatronic concept and product/system.

Consequently, according to the figure: Mechatronics, Micro-mechatronics and Nano-Mechatronics is synthesized by synergy sub-domains of mechanics,

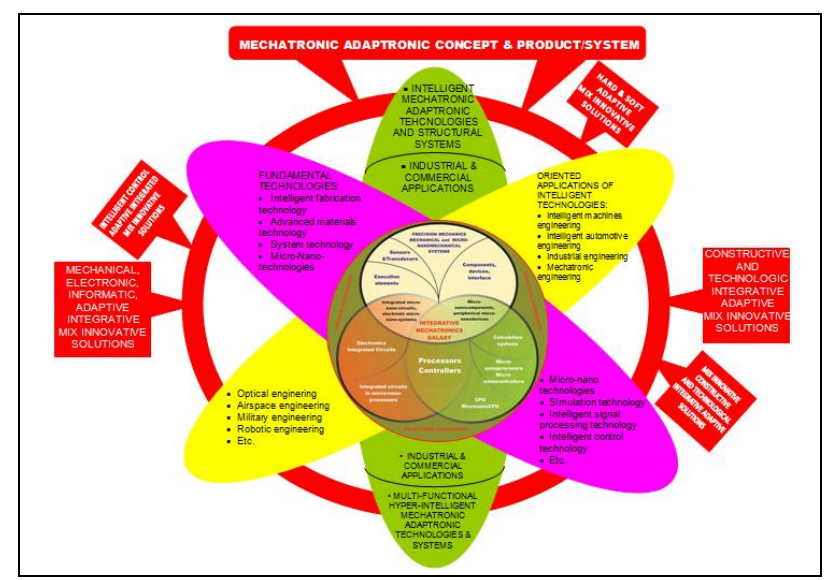

Fig. 2. The adaptronic mechatronic concept and product/system

micromechanics and nano-mechanics (systems, devices, mechanical connections, components, and so on.) electronics, including microelectronics and nanoelectronics (components, simple and integrated circuits, peripherals, interfaces, modules, sensors, transducers, amplifiers, transformers, switches, and so on.) and computer, including micro-informatics and nanoinformatics (hard systems, computer systems, processors, controllers, software systems, and so on. ) adaptation process, structural and functional development [3], integrates to meet new demands, conditions and effects, new mix innovative mechanical solutions, electronic and integrative adaptive mix innovative, new solutions integrated intelligent control and adaptive hardware and innovative new solutions mix adaptive software, the process of adaptation, integrating fundamental technologies for the development of appropriate technology highly competitive performance, and intelligent manufacturing technology, advanced materials technology, technology systems, micronanotechnologies, advanced simulation and modeling technologies, intelligent signal processing technology, intelligent control technology, and so on.; oriented applications of intelligent technologies include a wide range of scientific fields, such as intelligent machines engineering, intelligent car engineering, industrial engineering, mechatronics engineering, optical engineering, aerospace engineering, military engineering, robotics engineering, and so on.; applications of mechatronic adaptronic products / systems are summarized as a whole, in industrial and commercial applications, industrial results of advanced high-tech field Mechatronics Adaptronic are materialized in technologies and in structural intelligent mechatronic adaptronic systems and in multifunctional hyperintelligent mechatronic adaptronic technologies and systems, contributing to the sustainable development of the intelligent industry, of knowledge-based economy and information society.

\subsection{Intelligent functional and applicative structure for adaptronic integronics}

High-tech integronics domain developed in stages, depending on technical and technological requirements imposed by the new generation products and intelligent technologies and new industrial and commercial applications, assembling innovative mechatronics 
integronics vectors in terms of architectural mechatronics in a mix-innovative structure [4] and in a systemic integrated conception, cumulating constructive functional-decisional solutions, similar to human body, and evolving into a global innovative adaptive vector of concept and product or adaptronic integronic system (figure 3).

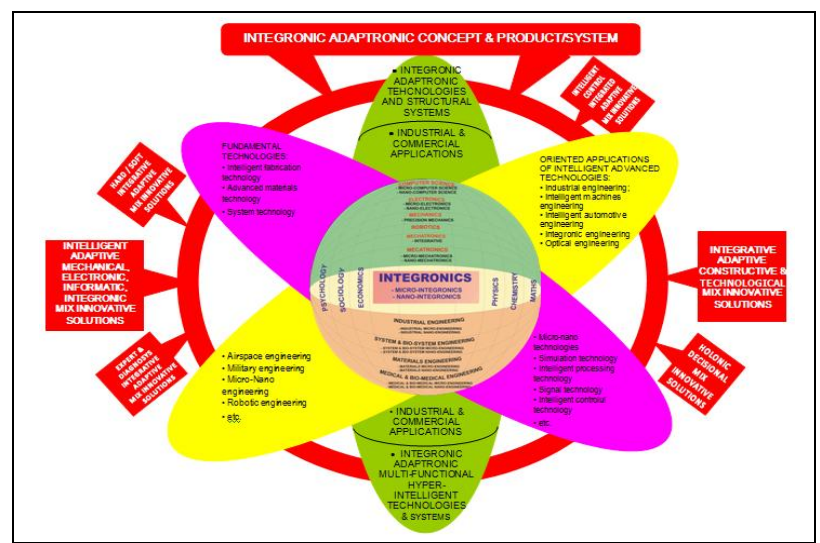

Fig. 3. Integronic adaptronic concept

The advanced high-tech intelligent field Integronics Adaptronics is based on the integronic adaptronic concept and product or system integrating multiinterdisciplinary technical knowledge and technological solutions applied to industrial and commercial intelligent adaptive completed and assembled structures, materials and systems. Consequently, according to the figure mentioned: Integronics, Micro-Integronics and NanoIntegronics is synthesized by the highly assembled technological combination of the following sub-fields: mechatronics (including micro-mecatronics and nanomecatronics) integrated mechatronics (including sensorics, actuatorics, digital interfaces, and so on.), robotics (including micro-robotics and nano-robotics), precision mechanics (including precision micromechanics and nano-mechanics), electronics (including micro-electronics and nano-electronics), informatics (including micro-informatics and nano-informatics) with other sciences (physics, chemistry, mathematics, economics, sociology, psychology and so on.), into an industrial-commercial applicative structure with industrial engineering (including industrial micro-nanoengineering) systems and bio-systems engineering, intelligent materials engineering (including micro-nano intelligent materials engineering) and medical and biomedical engineering (including medical and biomedical micro-nano-engineering), the "masterly" complete integration and adaptation to the creation and development of systemic assemblies and active-adaptive holonic new applications, conditions and effects, assembles of structural-functional-decisional and informational constructive and innovative new solutions of mix integrative adaptive technology, mix mechanical, electronic, computer, intelligent adaptive integronic innovative new solutions, new innovative mix adaptive integrated intelligent control solutions, new innovative integrative adaptive hardware and software solutions, new innovative integrative adaptive expert solutions and new innovative integrative adaptive diagnostic solutions and new innovative integrative adaptive mix holonic decision; at the same time, this integrative adaptation process includes fundamental integronic adaptronic technologies used in intelligent manufacturing and advanced materials technology, system technology, micro-nano technology, simulation technology, intelligent processing technology, signal technology, intelligent control technology, and so on; oriented applications of integronic adaptronic technologies include a wide matrix of application fields such as industrial engineering, intelligent machines engineering, intelligent car engineering, integronic engineering, optical engineering, aerospace engineering, micro-nano engineering, robotics engineering, and so on; applications of technology and intelligent integronic adaptronic structural systems and multi-hyper-intelligent integronic adaptronic systems are, as a whole, industrial and commercial applications, results of the advanced Adaptive Integronics are materialized in structural and multifunctional intelligent hyper-intelligent Adaptronic Integronic Technologies and Systems, which contribute to the development of the future intelligent industry, economy and society.

\subsection{Intelligent functional and applicative structure for robotic and micro-nano-robotic Adaptronics}

The high-tech field: "Robotic and micro-nano-robotic Adaptronics" was designed and architectured by medium, micro and nano-scale advanced technologies, intelligent advanced materials, multidisciplinary industrial engineering, intelligent control, high performance hardware and software, by developing nano-sciences and has been developed according to the new requirements, conditions and effects on the new information society. Constantly evolving, the "Robotic and micro-nano-robotic Adaptronics " field has develop skills and abilities for mastering any uncertainties within systems, sub-systems or components, monitoring realworld uncertainties bet on bet on the variable time, similar behaviours and interactions of biological systems human-robot or intelligent micro-nano-robot [5].

"Robotic and micro-nano-robotic Adaptronics" is depicted and structurally synthesized in Figure 4.

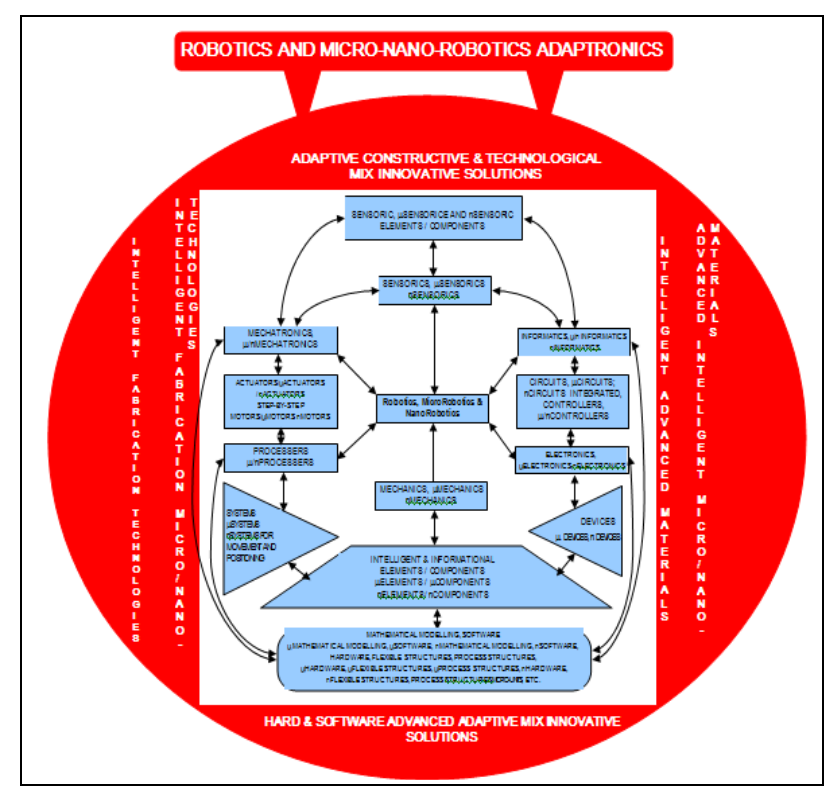

Fig. 4. Robotics and micro-nanorobotics adaptronics 
Consequently, according to the figure mentioned: the structural architecture for robotic and micro-nano-robotic adaptronics is synthesized by the mechanical synergy of major sub-domains (including micro-mechanics and nano-mechanics), sensors (including micro-sensors and nano-sensors), actuators (including micro-actuators and nano- actuators), displacement and positioning systems (including displacement and positioning micro-nanosystems), electronics (including micro-electronics and nano-electronics), informatics (including microinformatics and nano-informatics) and mathematical modeling and software (including micro-software and nano-software micro-nano-modelling).

The intelligent integrating science assembles mix innovative constructive and technological solutions and mix adaptive innovative solutions and mix innovative hardware and software technologies with advanced adaptive hardware and software solutions with intelligent manufacturing technologies [6] and intelligent manufacturing micro-nanotechnologies and advanced intelligent materials and advanced intelligent micro-nano materials; the results of the field: "Robotic and micronano-robotic Adaptronics" are materialized in intelligent adaptronic micro-robots and nano-robots; applications of robotic adaptronic products and technologies and micronano-robotic products and technologies are very broad and diverse and are designed for strategic and priority areas, especially the medical field, thus leading to visiting, diagnosis, operation, monitoring and evaluation at molecule or cell level.

Robotics and micro-nano robotics contribution in adptronic solutions is realised by adapting and integrating of technical and technological solutions very competitive in intelligent structural subsystems, micro electro mechanics and nano electro mechanics. In technological evolution, this intelligent and multifunctional structural systems have a long perspective in innovative applications, solving thus problems reffering to molecular dynamics for actions at a micro and nano scale and contructive approaches for volume processing and for surface processing in applications for processes and manufacturing to realise protypes, testing molds, multifunctional cip, etc.

\section{FUTURE RESEARCH PLANS}

Basis on fundamental and applicative researches, realised and implemneted in this paper, is designed these future research plans, comprising :

- development by extension and intensity of integrator adaptronic concepts to realise technological fusion of high-tech domains, to obtain new products and adaptronic systems for strategic industries, like military industry, aerospatial industry, automotive industry;

- adapting by integrating of ansamble parts of adaptronic systems with parts of intelligent technologies, to construct a flexible, holonic architecture;

- development and maturation of integrator vectors, of science and intelligent adaptronic technology, to realise adaptronic systems with autocomposition, autocorrection, autocontrol, autodiagnose, etc. for intelligent manufacturing and higher competitive of future.

To realise these future research plans are projected the steps to follow, thus :

- step 1. Laboratory research in a real and virtual space, of each adaptronic concepts, by creating new sciences, new technologies, new human resources with excellence qualifications ;

- step 2. Realization of fusions, demonstrate, simulation and intelligent modeling by creating models, prototypes or adaptronic unique adapted to goals and objectives of informational or future society;

- step 3. Projecting, realization and implementation of the results of adaptronic research to obtain products, systems, complex and adaptronic architecture conform to requests and future conditions.

\section{CONCLUSIONS}

As an integrative synthesis, ADAPTRONICS is an active technology structurally applicable in the most industries, is an opening of possibilities completely new, for development of products and base innovating systems, is a new mode of operating for changing, is a new construction of any kind structures, is a new approach of monitorising and influencing, is optimal cooperation between multi-interdisciplinarity and expertise from science and industry and is a complex integration between research-innovation- technological transfer and commercial application.

\section{REFERENCES}

[1] Bae, J., S., Siegler, T. M., Inman, D., J. (2005). Aerodynamics and staticaeroelastic charactristics of a variable-span morphing wing. AIAA J. Aircraft, Vol. 42, No. 2, pp. 528-534

[2] Gheorghe, G, Stiharu, I. (2011). NanoEngineering. Cefin Publishing House, ISBN 978-606-8261-15-7, pp. 9-140

[3] Navarro, X., Krueger, T., B., Lago,N. Micera, S, Stiegltz, T., Dario, R. (2005). A critical review of interfaces with the peripheral nervous systems for the control of neuroprostheses ad hybrid bionic systems. J. Periph, Nerv. Sys 10, pp 229-258

[4] Rijkhoff, N.J.M (2004). Neuroprostheses to threat neurogenic bladder disfunction: current status and future perspectives. Childs Nerv. Sys. 20, pp 75-86

[5] Sinkjaer, T., Haugland, M., Inmann, A., Hansen, M., Nielsen, K. $\mathrm{D}$ (2003). Biopotentials as command and feedback signals in functional electrical stimulation systems. Med-Eng-phis 25(1) pp 29-40

[6] Spencer, B.S.(2006). Incorporating the sense of smell into patient and haptic surgical simulators. IEEE-Trans inf.Technol. Biomed. 10(1) pp 168-173 